Relations industrielles

Industrial Relations

\title{
La CSN a quarante ans
}

\section{Jean Marchand}

Volume 16, numéro 4, octobre 1961

URI : https://id.erudit.org/iderudit/1021678ar

DOI : https://doi.org/10.7202/1021678ar

Aller au sommaire du numéro

\section{Éditeur(s)}

Département des relations industrielles de l’Université Laval

ISSN

0034-379X (imprimé)

1703-8138 (numérique)

Découvrir la revue

Citer ce document

Marchand, J. (1961). La CSN a quarante ans. Relations industrielles / Industrial Relations, 16(4), 471-474. https://doi.org/10.7202/1021678ar

Tous droits réservés ( Département des relations industrielles de l’Université Laval, 1961
Ce document est protégé par la loi sur le droit d'auteur. L’utilisation des services d'Érudit (y compris la reproduction) est assujettie à sa politique d'utilisation que vous pouvez consulter en ligne.

https://apropos.erudit.org/fr/usagers/politique-dutilisation/ 
des journaux quotidiens, et dans certaines entreprises de l'industrie de la boite de carton; que dans les entreprises où l'on imprime des quotidiens, les compagnons et apprentis des ateliers, les journalistes des salles de rédaction, les employés de bureaux et ceux des services de distribution sentent très bien la solidarité qui les unit et qui est nécessaire pour la solution de certains problèmes communs, comme les pensions, les assurances, les indemnités en maladie, la proportion de certaines augmentations de salaires, etc. Des problèmes professionnels différents se posent, bien sûr, mais ils sont réglés à l'intérieur des organismes syndicaux compétents, comme il se doit. Une fédération unique, groupant les divers syndicats de salariés dans ce puissant secteur économique, pourrait sans aucun doute protéger très efficacement tous ses membres et se situerait entre la matière première et le produit fini. Le projet vaut que l'on s'y arrête.

\section{La CSN a quarante ans}

\section{Jean Marchand}

Si notre Confédération n'a que quarante années d'existence, puisqu'elle fut fondée, à Hull, en 1921, notre mouvement a une histoire beaucoup plus longue. En effet, nous pouvons fixer au début du siècle la fondation de nos premiers syndicats dans l'industrie de la chaussure, à Québec. Dans la même période naissaient des syndicats dans la région du Saguenay et un peu plus tard à Hull, Trois-Rivières, Lachine, Thetford Mines, Montréal, etc. Ces syndicats se sont rapidement groupés en conseils centraux ou régionaux et ont même organisé des congrès généraux. Aux assises historiques de Hull, en 1921, étaient représentés des groupements syndicaux dont plusieurs avaient déjà une tradition bien établie et une longue expérience.

\section{Caractère du mouvement}

Notre mouvement a été profondément marqué et influencé par le milieu dans lequel il est né et s'est développé. On n'a qu'à songer aux forces qui remuaient la Province à cette période pour comprendre les tendances qui furent communiquées à notre organisation. La C.T.C.C., à ses débuts, était nettement nationaliste, confessionnelle, pro-corporatiste et les aumôniers y jouaient un rôle prédominant. Souvent l'action catholique prenait le pas sur l'action professionnelle et proprement syndicale. L'industrialisation était tenue en suspicion et nous relevons même des résolutions, lors des premiers congrès, contre l'exode rural et pour le retour à la terre.

L'invasion de la Province par les unions internationales a jeté beaucoup d'inquiétude dans les esprits et il n'y a aucun doute que les classes dirigeantes ont vu dans nos syndicats des instruments appropriés pour enrayer ce \& fléau». 
Mais, progressivement, l'action authentiquement ouvrière se fit sentir dans ces nouveaux cadres qui étaient offerts aux travailleurs.

La crise des années 30 a retardé, comme ce fut le cas pour les autres centrales syndicales, le développement de notre mouvement. Mais avec la guerre et le retour à la prospérité, un nouvel élan fut imprimé à l'organisation. L'adhésion plus nombreuse des travailleurs industriels contribua largement à faire mûrir la C.T.C.C. et à lui donner une nouvelle orientation.

Faire l'histoire de la C.T.C.C. c'est un peu faire l'histoire de la Province de Québec. Je ne crois pas que l'on puisse être justifié de s'étonner ou se scandaliser des voies qu'a suivies la C.T.C.C. avant de parvenir à sa taille et son statut actuels. On se demande même si elle aurait pu exister autrement. Ceux qui nous ont précédés ont fait ce qu'ils ont pu avec les instruments dont ils disposaient et la matière sur laquelle ils devaient travailler. Je crois qu'il faut rendre hommage à leur courage, leur patience, leur dévouement et leur esprit de foi.

\section{RÉalisations}

On pourrait faire une compilation impressionnante des réalisations de la C.S.N. tant dans le domaine professionnel, économique, législatif que social. Je veux me limiter, toutefois, à une seule que je considère majeure.

C'est notre mouvement, qui, à mon avis, a fait accepter le syndicalisme par les travailleurs de la Province de Québec et la société québécoise. Les principes auxquels il adhérait et ses titres de naissance lui ont permis de pénétrer profondément dans le milieu sans susciter l'opposition que provoquaient les autres organisations syndicales. Cela a permis à une foule de travailleurs de se former syndicalement et de goùter aux bienfaits de l'action collective. Ainsi se sont préparés les éléments qui devaient constituer le ferment et alimenter le dynamisme de l'organisation syndicale de chez nous.

\section{Changements}

La C.S.N. a changé considérablement depuis 1921 et il faut s'en réjouir. Il est normal qu'un corps, qui grandit et se développe, se transforme malgré souvent les regrets nostalgiques des parents qui continuent de rêver aux heures sereines du berceau et de l'enfance.

La C.S.N. est adulte et elle doit régler des problèmes d'adulte. Si elle a de la reconnaissance envers tous ceux qui ont contribué à faire ce qu'elle est, cette reconnaissance ne peut l'excuser de manquer à son devoir ou d'échapper à ses responsabilités.

En 1921, l'économie de la province était encore dominée par le secteur rural. Aujourd'hui l'économie canadienne est industrielle et les phénomènes économiques ont largement débordé les limites de la région, de la province et même du pays. Les entreprises ont atteint, dans un grand nombre de cas, des tailles de mastodonte et se sont ramifiées souvent en un grand nombre d'unités de production. Les frontières économiques ne coïncident plus avec les frontières politiques. 
En 1921, la population de la province de Québec était beaucoup plus homogène et il pouvait être légitime de songer à un mouvement syndical qui trouverait son appui chez les seuls Canadiens français catholiques. Les changements démographiques, l'urbanisation, les impératifs de la solidarité syndicale, les modifications dans les structures industrielles, les mesures législatives nouvelles, ont obligé la C.S.N. à reviser ses positions et à s'adapter aux nouvelles conditions. Il ne s'agit pas d'une trahison du passé, au contraire. Le plus bel hommage que l'on peut rendre au passé est de poser des gestes qui conserveront la vitalité et assureront le développement de l'oeuvre qu'il a léguée.

La Confédération des syndicats nationaux n'est plus, depuis l'an dernier, une organisation confessionnelle bien qu'elle continue de s'inspirer, dans son action, des principes chrétiens. Cet aboutissement est le résultat d'une longue et prudente évolution. Les aumôniers ont conservé leur statut, mais les officiers, les permanents syndicaux et les militants sont généralement assez bien outillés pour assumer toutes leurs responsabilités, déchargeant ainsi les conseillers moraux d'une tâche que les circonstances historiques les avaient obligés d'accomplir.

La Confédération des syndicats nationaux veut, suivant la formule la plus appropriée et la plus efficace, étendre ses cadres aux dimensions du Canada. Elle croit fermement que les travailleurs canadiens désirent une organisation syndicale authentiquement canadienne qui collaborera loyalement avec les autres centrales nationales et internationales.

La Confédération des syndicats nationaux s'oppose aux distinctions injustes à cause de la langue, de la race, de la religion et du sexe. Elle ouvre largement ses portes à tous les travailleurs canadiens qui partagent ses idéaux.

La Confédération des syndicats nationaux croit à la démocratie et elle est convaincue qu'elle constitue une école modèle dans ce domaine. A cause de la grande autonomie de ses corps affiliés, et aussi parce que tous les organismes de direction et d'administration sont à la portée des travailleurs, elle considère que c'est dans son sein que ces derniers pourront mieux se développer et assumer des responsabilités d'hommes. Si elle déplore la dépersonnalisation des travailleurs et la déshumanisation du travail dans la grande entreprise nord-américaine, elle est profondément inquiète de constater qu'un phénomène parallèle se produit dans des unités syndicales trop grandes, trop centralisées et coupées par des frontières qui gênent les contacts et les communications. Les avantages aléatoires que ces unités peuvent offrir ne compensent certainement pas pour les valeurs qu'elles mettent en péril.

La Confédération des syndicats nationaux croit à la nécessité de l'action syndicale au plan mondial et elle veut y participer de plus en plus. Elle voit là un moyen très efficace d'atteindre les objectifs de justice et de paix que propose Jean XXIII dans « Mater et Magistra ».

La Confédération des syndicats nationaux croit aux valeurs spirituelles de l'homme et n'admet pas qu'on les méconnaisse dans la construction de la cité terrestre. 
La Confédération des syndicats nationaux reconnaît la vertu salvatrice de la culture et de l'éducation et c'est pourquoi elle veut contribuer à en répandre les bienfaits le plus possible.

La Confédération des syndicats nationaux croit à la possibilité de la paix, et condamne la guerre sous toutes ses formes comme moyen de règlement des conflits internationaux. Elle s'oppose particulièrement à l'utilisation des armes nucléaires.

La Confédération des syndicats nationaux a plusieurs autres objectifs sociaux, économiques, professionnels et politiques. Sa déclaration de principe les énumère et les définit.

Pour atteindre ces objectifs, notre Confédération possède, à tous les échelons, un nombre considérable d'officiers responsables et bien formés. Ses conseillers techniques, ses organisateurs, ses agents d'affaires, son personnel administratif et ses directeurs de service sont compétents, dévoués et dynamiques. Nous possédons un journal dont le tirage dépasse les quatre-vingts mille. La C.S.N. compte au-delà de cinq cent cinquante syndicats affiliés qui groupent environ 100,000 membres distribués dans toutes les branches de l'industrie, du commerce et des services.

\title{
LE PROFIT COMPTABLE
}

\author{
fiction ou réalité?
}

PAR

ALPHONSE RIVERIN

1 volume de 139 pages. Prix: $\$ 2.50$

\author{
Les Presses de l'Université Laval, \\ 28, rue Ste-Famille, \\ Québec.
}

